\title{
ФУНКЦИОНАЛЬНАЯ МОДЕЛЬ ОЦЕНКИ УРОВНЯ РАЗВИТИЯ КОРПОРАТИВНОЙ КУЛЬТУРЫ
}

\section{FUNCTIONAL MODEL FOR ASSESSING THE LEVEL OF DEVELOPMENT OF CORPORATE CULTURE}

\section{Nemtsov}

Summary. This article provides an example of building a graphic profile of the level of development of corporate culture. The approach of $D$. Denison and his colleagues was taken as the basis of the model building mechanism. The main distinguishing feature in the proposed model of corporate culture of the organization is a functional approach.

Keywords: corporate culture, functions of Corporate culture, graphic profile of Corporate culture, level of development of Corporate culture, D. Denison model.

\section{Введение}

H а сегодня в Российских предприятиях промышленной и не только отраслях предпринимаются попытки оптимизации процессов и повышения операционной эффективности путем внедрения различных концепций организации бизнеса, но только в исключительных случаях они приводят к значимым положительным результатам. Это делает актуальным исследование факторов, влияющих на восприимчивость данных концепций отечественными предприятиями. Одним из таких значимых факторов является уровень развития Корпоративной культуры, определение которого способствует правильному выбору стратегии внедрения концепций.

В последние годы вопрос корпоративной культуры приобретает особую значимость, привлекая к себе внимание как теоретиков, так и практиков управления. В условиях формирования рыночных отношений, усиления конкуренции, глобализации и интеграции стран в мировое сообщество, предприятия вынуждены постоянно эволюционировать и быстро реагировать на изменения [1]. Движущей силой в этих процессах выступает корпоративная культура, которая объединяет предприятие и персонал единственной миссией, единственной философией, стратегией развития, принципами, ценностями, традициями, создает репутацию в деловом мире, формирует его имидж, повышает конкурентоспособность и обеспечивает конкурентное преимущество.

\author{
Немцов Денис Владимирович \\ Аспирант, Университет «Синергия» \\ alesana.sanders@gmail.com
}

Аннотация. В данной статье приведен пример построения графического профиля уровня развития корпоративной культуры. За основу механизма построения модели был взят подход Д. Денисона и его коллег. Главной отличительной особенностью в предлагаемой модели Корпоративной культуры организации является функциональный подход.

Ключевые слова: корпоративная культура, функции Корпоративной культуры, графический профиль Корпоративной культуры, уровень развития Корпоративной культуры, модель Д. Денисона.

Корпоративная культура является специфической формой существования взаимосвязанной системы, включающей в себя: во-первых, иерархию ценностей, доминирующих среди сотрудников организации; во-вторых, совокупность способов их реализации, которые преобладают в ней на определенном этапе развития [2].

Но все приведенные выше примеры является способом качественной оценкой Корпоративной культуры, а именно определением типа Корпоративных культур и присвоения им набора особенностей отличающих друг от друга. Данные методы являются неподходящими для получения информации связанной с конкретным уровнем развития Корпоративной культуры, поскольку носят качественный характер. В этой связи была доработана модель Корпоративной культуры Д.Денисона и его коллег, которая включает в себя четыре фактора (адаптивность, миссию, взаимодействие и вовлеченность), оказывающих, по мнению Д. Денисона, наибольшее влияние на эффективность Корпоративной культуpы.

В качестве доработки модели Д. Денисона, учитывая рационально-прагматический подход к Корпоративной культуре можно выделить её функции и индикаторы, влияющие на результативность выполнения данных функций (см. таблица 1).

Рассмотрим подробно каждую функцию и выбранные индикаторы: 
Таблица 1. Функции Корпоративной культуры и их индикаторы

\begin{tabular}{|c|c|}
\hline Функции корпоративной культуры & Индикаторы эффективности \\
\hline Мотивационная & $\begin{array}{l}\text { 1. Оценка работы сотрудников } \\
\text { 2. Решение проблем } \\
\text { 3. Качество исполнения работы }\end{array}$ \\
\hline Управленческая & $\begin{array}{l}\text { 1. Постановка целей } \\
\text { 2. Стратегическое планирование } \\
\text { 3. Координация }\end{array}$ \\
\hline Адаптивная & $\begin{array}{l}\text { 1. Организационное обучение } \\
\text { 2. Чувство принадлежности } \\
\text { 3. Перемены в компании } \\
\end{array}$ \\
\hline Системообразующая & $\begin{array}{l}\text { 1. Работа в команде } \\
\text { 2. Понимание взаимосвязей } \\
\text { 3. Внутренняя информация } \\
\end{array}$ \\
\hline Вовлекающая & $\begin{array}{l}\text { 1. Развитие способностей } \\
\text { 2. Система поощрений } \\
\text { 3. Удовлетворенность от работы } \\
\end{array}$ \\
\hline Идентифицирующая & $\begin{array}{l}\text { 1. Ответственность и полномочия } \\
\text { 2. Ценности } \\
\text { 3. Согласие } \\
\end{array}$ \\
\hline Имиджевая & $\begin{array}{l}\text { 1. Ориентир на потребителя } \\
\text { 2. Психологическое состояние } \\
\text { 3. Положительное отношение к компании }\end{array}$ \\
\hline
\end{tabular}

Характеристика «Мотивационной функции» указывает на степень отдачи персонала в выполнении поставленных задач, которая способствуют качественному и эффективному достижению целей организации

Мотивирующая функция включает индикаторы:

1. Оценка работы сотрудников - характеризует справедливую мотивирующую и стимулирующую надбавку за достижение каких либо результатов;

2. Решение проблем - характеризует ситуацию, когда сотрудники самостоятельно оказывают инициативу в решении возникающих проблем;

3. Качество исполнения работы - характеризует ситуации, когда дефектные продукции не передается, не изготавливается и не принимается. Так же подразумевает наличия моратория на ошибки.

Характеристика «Управленческой функции» указывает на степень проработки норм и правил управления подразделениями или командами/рабочими группами.

Обозначим индикаторы, входящие в управленческую функцию:

1. Формализация целей - предполагает выбор ясных, четко обозначенных целей и задач, которые согласуются со стратегией и миссией предприятия, а также дают возможность каждому работку осознать вектор его работы, понять, каким образом его деятельность влияет на достижение целей и задач предприятия в целом [3]
2. Разработка стратегического плана. Данный индикатор включает в себя четко выбранные стратегические установки, которые определяют целенаправленность действий предприятия [4]

3. Координация - отражает четкость соблюдения норм и правил работы команд или рабочих групп, а так же быстрое и адекватное реагирование на получение обратной связи.

Характеристика «Адаптивной функции» свидетельствует о способности организации осуществлять нововведения, а также возможности управленческого звена определять свои ошибки и извлекать из них уроки, навыки при необходимости быстро вливать новых сотрудников в коллектив и рабочий процесс.

Адаптивная функция включает индикаторы [5]:

1. Организационное обучение. Этот индикатор свидетельствует о том, что предприятие способно идентифицировать и верно интерпретировать сигналы внешнего окружения и на основании этого принимать действенные решения, направленные на повышение эффективности бизнеса.

2. Чувство принадлежности - показывает, степень чувства принадлежности сотрудника к достигнутым результатам предприятия.

3. Возможность меняться - это означает, что предприятие способно создавать эффективные механизмы, направленные на удовлетворение потребностей в переменах и совершенствовании бизнес-процессов. 
Таблица 2. Шкала оценки уровня эффективности Корпоративной культуры

\section{Оценка в баллах}

$0-0,25$

$0,26-0,5$

$0,51-0,75$

$0,76-1$

\section{Уровень развития корпоративной культуры}

Очень низкий

Низкий

Средний

Высокий

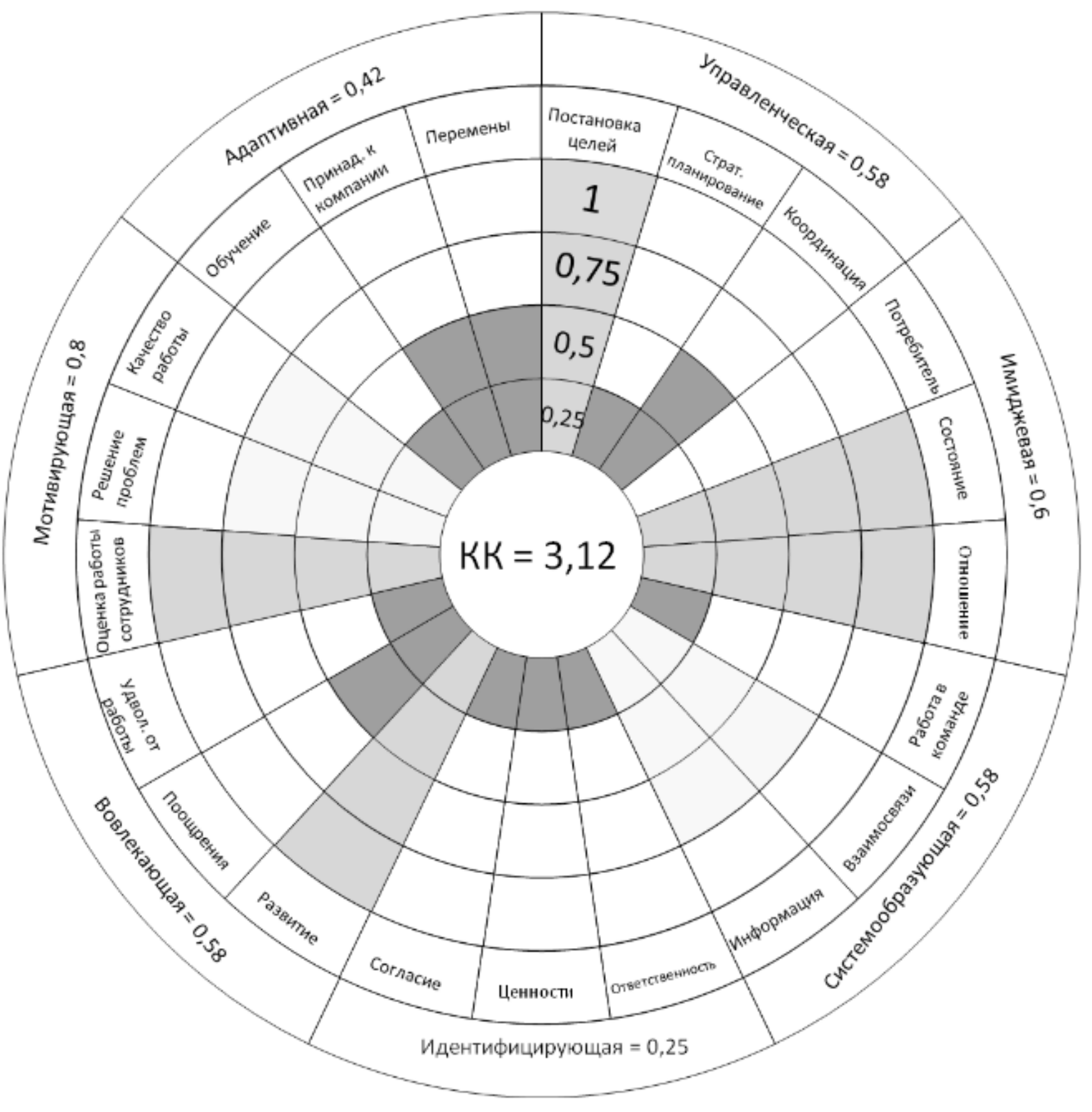

Рис. 1. Пример графического профиля оценки эффективности корпоративной культуры 
Характеристика «Системообразующей функции» указывает на степень проработки и системности правил взаимодействия как внутри конкретного подразделения так на предприятии в целом [6]

Системообразующая функция включает индикаторы:

1. Способность работать в команде - свидетельствует о том, что работники компании в процессе совместной работы ориентированы на эффективное сотрудничество и взаимную поддержку, а не на конкуренцию. При этом каждый работник ощущает свою личную ответственность за решение общекомандных задач.

2. Понимание взаимосвязей - означает прозрачность всех необходимых для понимания сотрудников процессов.

3. Внутренняя информация - означает что новая информация о реализации проекта или достижения предприятием каких-либо результатов, а так же информация касающаяся исполнительской деятельности, доходит до всех сотрудников в оперативные и сроки и необходимом объеме.

«Вовлекающая функция» показывает о степени участия работников в деятельности предприятия. Кроме того, она отражает состояние, при котором персонал чувствует, что его деятельность напрямую связана с целями предприятия, что у каждого работника есть полномочия, что высоко ценится работа в команде, а приоритет, в свою очередь отдается развитию и усовершенствованию человеческих способностей.

Вовлекающая функция включает индикаторы: [7]

1. Развитие навыков, повышение квалификации означает, что предприятие регулярно инвестирует в профессиональный рост своего персонала, с целью повышения конкурентоспособность, а также роста эффективности решения определенных производственных задач.

2. Система поощрений - говорит о наличии работоспособной системы дополнительного стимулирования сотрудников на выполнения задач не входящих в прямые обязанности.

3. Удовлетворенность от работы - характеризует моральное удовлетворение сотрудников от как самого процесса исполнения и решения поставленных задач так и от полученных результатов работы.

Характеристика «Идентифицирующей функции» указывает на степень понимания каждым сотрудником его необходимости предприятию и отождествлению с самой организацией
Идентифицирующая функция характеризуется такими индикаторами:

1. Полномочия и ответственность - отражает ситуацию, когда у сотрудников компании есть инициатива, кроме того они располагают достаточным объемом возможностей для того, чтобы влиять на протекающие рабочие процессы, в которых они участвуют. [8]

2. Ценности - является свидетельством того, что персонал предприятия разделяет установленные принципы корпоративной культуры и определенный ею набор ценностей.

3. Согласие - характеризует ситуацию, когда что персонал предприятия способен достичь консенсуса в спорных ситуациях. Возникающие конфликты быстро улаживаются. [9]

Характеристика «Имиджевой функции» указывает на степень привлекательности предприятия как для заказчика для и для потенциальных профессиональных сотрудников, а так же на формирование внутреннего положительного образа.

Имиджевая функция включает индикаторы:

1. Ориентир на потребителя - характеризует степень удовлетворения потребителей продукции, выпускаемой предприятием, тем самым говоря о степени привлекательности

2. Психологическое состояние - характеризует степень морального состояния сотрудник при нахождении на рабочем месте, при выполнении должностных обязанностей или взаимоотношении с другими сотрудниками

3. Положительное отношение к компании - говорит, что сотрудники готовы отстаивать честь, а так же интересы предприятия, в котором они работают.

Для оценки индикаторов эффективности по каждой функции необходимо провести анкетирование, состоящие из утверждений, описывающих различные аспекты Корпоративной культуры. Получив среднее значение по каждому индикатору функции, путем выведение среднего значения мы формируем значение эффективности функции в целом.

$$
Э \Phi=\frac{И 1+И 2+И 3}{3}
$$

где ЭФ - количественный показатель эффективности функции;

И1, И2, ИЗ - индикаторы функции.

Общий количественный показатель состояния Корпоративный культуры рассчитывается путем получения суммы значений эффективности всех функций, где мак- 
симальный показатель будет равен 7, а минимальный 0. Полученные показатели можно оценивать в соответствии со шкалой развития Корпоративной культуры, представленной в таблице 2.

Итоговый графический профиль оценки развития и эффективности корпоративной культуры предприятия представлен на рисунке 1. Так же одной из особенностей графического изображения эффективности Корпо- ративной культуры является правильное расположение функций по окружности. Представленный способ делит графический профиль на 2 полярные группы, предложенные в модели Д. Денисона:

1. Группа направления фокуса Корпоративной культуры на внешние или внутренние качества;

2. Группа реакции Корпоративной культуры на воздействия путем сохранения стабильности или гибкости самой системы.

\section{ЛИТЕРАТУРА}

1. Клещев А. Г. Развитие корпоративной культуры предприятия. Кострома: 06-во «Знание», 1999.

2. Кучкаров 3.А., Шаляпина С.К, Левенец В. В. Автоматизированное проектирование системы управления персоналом. // Справочник по управлению персоналом. 2002, № 1.

3. Спивак В. А. Корпоративная культура. СПб: Питер, 2001. 10. Тейлор Ф. У. Принципы научного менеджмента / пер. с англ. М.: Контроллинг, 1991.

4. Файоль А. Общее и промышленное управление / пер с франц. М.: Контоллинг, 1992.

5. Davis S. Managing corporate culture. Cambridge, MA: Ballinger. 1984.

6. Eisen A. The meanings and confusions of Weberian rationality, British Journal of Sociology № 29, 1978.

7. Kotter J.P., Heskett J. L. Corporate Culture and Performance. N.Y.: The Free Press. 1992.

8. Sathe V. Culture and related corporate realities: Text, cases and readings on organizational entry, establishment, and change. Homewood, IL: Irwin, 1985.

9. Schein E. H. Organizational culture and leadership. The Jossey-Bass Business \& management series, 2004.

10. Smircich L. Concepts of Culture and Organizational Analysis// Administrative Science Quarterly. 1983. № 28.

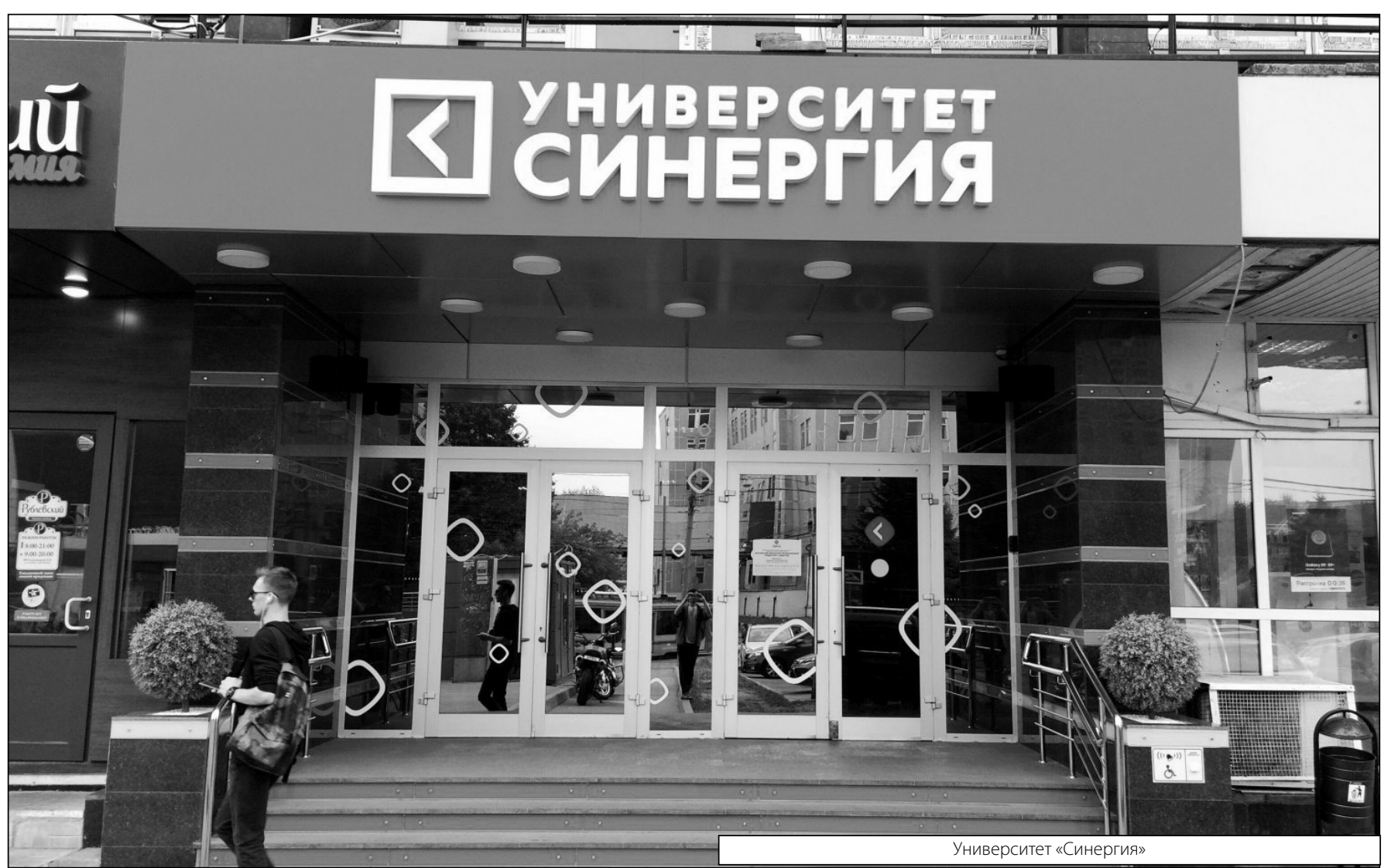

